\title{
The Association Reaction of Ion Radicals with Neutral Molecules. V. Hydrogen Bonding Equilibria between Anion Radicals of Substituted Nitrobenzenes and Benzophenones with Hydroxylic Compounds
}

\author{
Morten Svaan and Vernon D. Parker* \\ Laboratory of Organic Chemistry, Norwegian Institute of Technology, University of Trondheim, \\ N-7034 Trondheim-NTH, Norway
}

\begin{abstract}
Svaan, Morten and Parker, Vernon D., 1986. The Association Reaction of Ion Radicals with Neutral Molecules. V. Hydrogen Bonding Equilibria between Anion Radicals of Substituted Nitrobenzenes and Benzophenones with Hydroxylic Compounds. - Acta Chem. Scand. B 40: 36-39.
\end{abstract}

Equilibria (i) of the anion radicals of substituted nitrobenzenes

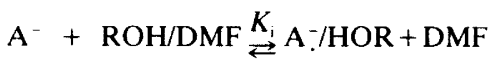

and benzophenones with water and methanol in DMF were studied at temperarures ranging from 273 to $298 \mathrm{~K}$. Equilibrium constants $K_{\mathrm{i}}$ were observed to depend upon the electronic effect of the para substituent and increase with increasing electron donating ability although Hammett plots were not linear. With electron donating substituents $\left(K_{\mathrm{i}}\right)_{\mathrm{MeOH}} /\left(K_{\mathrm{i}}\right)_{\mathrm{HOH}}$ was always greater than unity but was less than 1 with strongly electron with-drawing $\mathrm{NO}_{2}$ as the para substituent. In general the equilibrium constant ratios were greater for benzophenone than for nitrobenzene anion radicals. Enthalpies and entropies for reaction (i) are reported.

It is now well established that anion radicals of aromatic compounds form $1 / 1$ hydrogen bonded complexes with water and alcohols in aprotic solvents such as acetonitrile and $N, N$-dimethylformamide. ${ }^{1-4}$ When the hydroxylic compound, $\mathrm{ROH}$, is present at concentrations of the order of $1 \mathrm{M}$ or less, equilibrium (1) lies far to the right and the concentration of free $\mathrm{ROH}$ is quite low.

Solvent $+\mathrm{ROH} \underset{K_{1}}{\rightleftarrows}$ Solvent/HOR.

Because of the relatively strong hydrogen bond between the solvent and $\mathrm{ROH}$, equilibrium constants for reaction (2)

$$
\mathrm{A}^{-}+\quad \text { Solvent/HOR } \underset{K_{2}}{\rightleftarrows} \mathrm{A}^{-} / \mathrm{HOR}+\text { solvent }
$$

\footnotetext{
*To whom correspondence should be addressed.
}

\footnotetext{
36 Acta Chemica Scandinavica B 40 (1986) 36-39
}

are sometimes so small that the equilibria cannot be detected by the measurement of the reversible potentials for the formation of the anion radicals, $\mathrm{A}^{-}$. It is only in cases where the charge in $\mathrm{A}^{-}$is somewhat localized on heteroatoms that $K_{2}$ is measurable, i.e. of the order of 1 or greater. Previous papers in this series have dealt with equilibria of benzaldehyde ${ }^{1}$ and substituted benzaldehydes ${ }^{4}{ }^{4}$ of acetophenone ${ }^{2}$ and of benzylidenemalononitrile ${ }^{3}$ anion radicals. In this paper we summarize the results of reversible potential measurements on a series of substituted nitrobenzenes and a series of substituted benzophenones in DMF in the presence of water and methanol. 


\section{Results and discussion}

Equilibrium constants and thermodynamic parameters for the association of water and methanol with substituted nitrobenzene anion radicals (eqn. 3) are summarized in Table 1.

$p-\mathrm{X}-\mathrm{C}_{6} \mathrm{H}_{4} \mathrm{NO}_{2}^{-}+\mathrm{ROH} / \mathrm{DMF}$

$\stackrel{K_{3}}{\rightleftarrows} p-\mathrm{X}-\mathrm{C}_{6} \mathrm{H}_{4} \mathrm{NO}_{2}^{-} / \mathrm{HOR}+\mathrm{DMF}$

$p-\mathrm{X}-\mathrm{C}_{6} \mathrm{H}_{4} \mathrm{COPh}^{-}+\mathrm{ROH} / \mathrm{DMF}^{K_{4}}$

$p-\mathrm{X}-\mathrm{C}_{6} \mathrm{H}_{4} \mathrm{COPh}^{-} / \mathrm{HOR}+\mathrm{DMF}$
The corresponding data for the reactions (eqn. 4) of substituted benzophenone anion radicals are gathered in Table 2. As was observed to be the case with substituted benzaldehyde anion radicals, ${ }^{4}$ the equilibrium constants increase with the increasing electron donating character of the para substituents. Plots of $\log K_{\mathrm{X}} / K_{\mathrm{H}}$, where the subscripts indicate tha para substituent, $v s . \sigma_{\mathrm{p}}$ are illustrated in Figs. 1 and 2. The plots show that the attempted Hammett correlations are very qualitative and values of the Hammett reaction constants, $\varrho$, cannot be assessed.

It was pointed out by a referee that the effect

Table 1. Equilibrium constants and thermodynamic parameters for hydrogen bonding equilibria between $p-X-$ nitrobenzene anion radicals and hydroxylic compounds. ${ }^{a}$

\begin{tabular}{|c|c|c|c|c|c|c|}
\hline$x$ & $\begin{array}{l}K\left(\mathrm{H}_{2} \mathrm{O}\right) \% \\
\mathrm{M}^{-1}\end{array}$ & $\begin{array}{l}\mathrm{K}\left(\mathrm{CH}_{3} \mathrm{OH}^{2}\right. \\
\mathrm{M}^{-1}\end{array}$ & $\begin{array}{l}\Delta H^{\circ}\left(\mathrm{H}_{2} \mathrm{O}\right) / \\
\mathrm{kcal} \mathrm{mol}^{-1}\end{array}$ & $\begin{array}{l}\Delta H^{\circ}\left(\mathrm{CH}_{3} \mathrm{OH}\right) / \\
\mathrm{kcal} \mathrm{mol}{ }^{-1}\end{array}$ & $\begin{array}{l}\Delta S^{o}\left(\mathrm{H}_{2} \mathrm{O}\right) / \\
\text { cal K}^{-1} \mathrm{~mol}^{-1}\end{array}$ & $\begin{array}{l}\Delta S^{\circ}\left(\mathrm{CH}_{3} \mathrm{OH}\right) / \\
\text { cal K}^{-1} \mathrm{~mol}^{-1}\end{array}$ \\
\hline H & 2.33 & 6.11 & -0.443 & -2.66 & 0.060 & -6.14 \\
\hline $\mathrm{CH}_{3}$ & 2.18 & 5.00 & 1.87 & -0.954 & 8.38 & -0.290 \\
\hline $\mathrm{CN}$ & 0.88 & 1.66 & 0.630 & -3.48 & 2.04 & -11.7 \\
\hline $\mathrm{COCH}_{3}$ & 1.38 & 3.00 & -2.71 & -4.77 & -9.29 & -15.2 \\
\hline $\mathrm{COPh}$ & 1.31 & 0.79 & -3.70 & -1.73 & -13.0 & -6.79 \\
\hline $\mathrm{CO}_{2} \mathrm{CH}_{3}$ & 1.20 & 1.42 & -0.496 & -1.13 & -1.45 & -3.42 \\
\hline $\mathrm{N}\left(\mathrm{CH}_{3}\right)_{2}$ & 5.42 & 10.4 & -3.81 & -2.76 & -10.6 & -5.45 \\
\hline $\mathrm{NO}_{2}$ & 0.35 & 0.28 & -2.17 & -2.62 & -9.98 & -12.1 \\
\hline $\mathrm{NO}_{2}$ (meta) & 1.42 & & -6.37 & & -22.6 & \\
\hline $\mathrm{OCH}_{3}$ & 2.94 & 6.82 & 1.14 & -2.13 & -2.01 & -3.98 \\
\hline
\end{tabular}

${ }^{a}$ From reversible potential measurements by phase selective second harmonic a.c. voltametry.

${ }^{D}$ At $273.2 \mathrm{~K}$.

Table 2. Equilibrium constants and thermodynamic parameters for hydrogen bonding equilibria between $p-X-$ benzophenone anion radicals and hydroxylic compounds. ${ }^{a}$

\begin{tabular}{lllllll}
\hline $\mathrm{X}$ & $\begin{array}{l}K\left(\mathrm{H}_{2} \mathrm{O}\right)^{\circ} \\
\mathrm{M}^{-1}\end{array}$ & $\begin{array}{l}K\left(\mathrm{CH}_{3} \mathrm{OH} \%\right. \\
\mathrm{M}^{-1}\end{array}$ & $\begin{array}{l}\Delta H^{\circ}\left(\mathrm{H}_{2} \mathrm{O}\right) / \\
\mathrm{kcal} \mathrm{mol}^{-1}\end{array}$ & $\begin{array}{l}\Delta H^{\circ}\left(\mathrm{CH}_{3} \mathrm{OH}\right) / \\
\mathrm{kcal} \mathrm{mol}^{-1}\end{array}$ & $\begin{array}{l}\Delta S^{\circ}\left(\mathrm{H}_{2} \mathrm{O}\right) / \\
\mathrm{cal} \mathrm{K}^{-1} \mathrm{~mol}^{-1}\end{array}$ & $\begin{array}{l}\Delta S^{\circ}\left(\mathrm{CH}_{3} \mathrm{OH}\right) / \\
\mathrm{cal} \mathrm{K}^{-1} \mathrm{~mol}^{-1}\end{array}$ \\
\hline $\mathrm{H}$ & 3.81 & 12.2 & -1.43 & -0.790 & -2.55 & 2.09 \\
$\mathrm{CH}$ & 5.64 & 15.2 & -3.56 & -1.53 & -9.62 & -0.205 \\
$\mathrm{CN}$ & 1.13 & 2.17 & -4.18 & -8.92 & -15.0 & -31.1 \\
$\mathrm{COPh}$ & 0.84 & 1.25 & -0.728 & -4.14 & -3.02 & -14.7 \\
$\mathrm{~N}_{3}\left(\mathrm{CH}_{3}\right)_{2}$ & 5.47 & 23.3 & -0.701 & -2.54 & 0.814 & -3.03 \\
$\mathrm{NO}_{2}$ & 1.31 & 0.79 & -3.70 & -1.73 & -13.0 & -6.79 \\
$\mathrm{OCH}_{3}$ & 4.26 & 18.1 & -0.575 & -2.53 & 0.771 & -3.49 \\
\hline
\end{tabular}

${ }^{a}$ From reversible potential measurements by phase selective second harmonic a.c. voltametry.

${ }^{b}$ At $273.2 \mathrm{~K}$. 

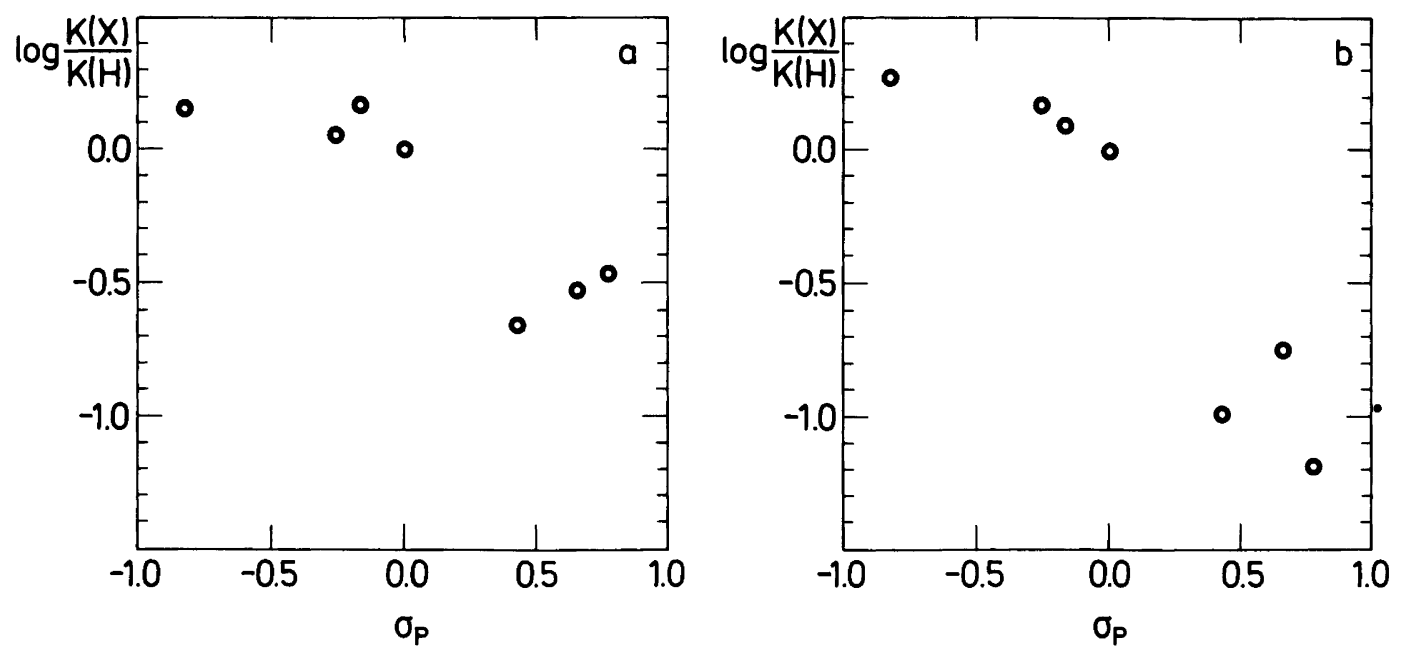

Fig. 1. Hammett plots for the hydrogen bonding equilibria of substituted benzophenone anion radicals with (a) water and (b) methanol in DMF.
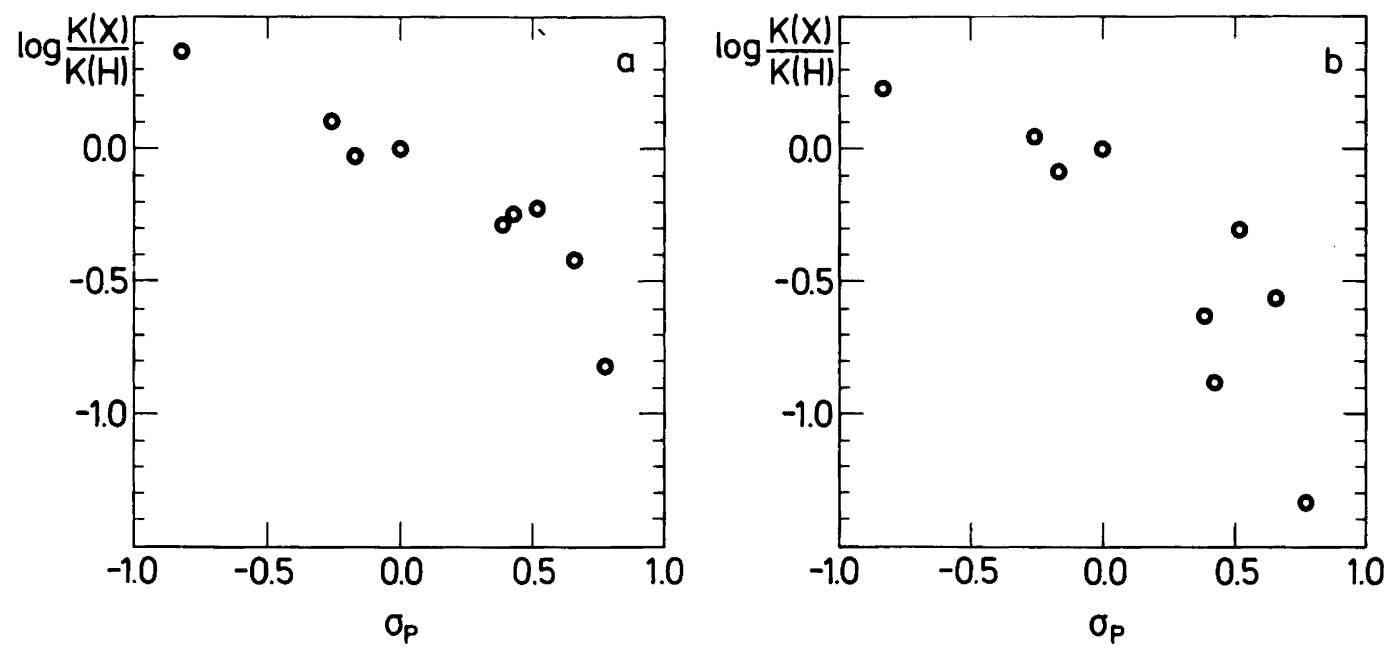

Fig. 2. Hammett plots for the hydrogen bonding equilibria of substituted nitrobenzene anion radicals with (a) water and (b) methanol in DMF.

of substituents fall into two groups, that of donors and that of acceptors, without any strong relationship to sigma within either group. A possible explanation is that with donors hydrogen bonding is principally at the nitro (nitrobenzenes) or carbonyl (benzophenones) groups while with acceptor substituents charge is also distributed over the substituent and hydrogen bonding takes place at these sites as well.

The enthalpies and entropies for reactions 3 and 4 are generally, but not always negative. There does not appear to be any relationship between the magnitude of $K$, at $273.2 \mathrm{~K}$, and $\Delta H^{\circ}$ for the reactions. This, of course, results in the 
Table 2. Equilibrium constant ratios for the association of methanol and water with anion radicals.

\begin{tabular}{lcccc}
\hline & & \multicolumn{3}{c}{$K_{\text {MoOH }}^{a} K_{\mathrm{H} 2}^{a} \mathrm{O}$} \\
\cline { 3 - 5 } $\mathrm{X}$ & $\mathrm{\sigma}_{\mathrm{p}}$ & $\mathrm{PhCOC}_{6} \mathrm{H}_{4} \mathrm{X}$ & $\mathrm{O}_{2} \mathrm{NC}_{6} \mathrm{H}_{4} \mathrm{X}$ & $\mathrm{OHCC}_{6} \mathrm{H}_{4} \mathrm{X}^{b}$ \\
\hline $\mathrm{N}^{\mathrm{C}}\left(\mathrm{CH}_{3}\right)_{2}$ & -0.83 & 4.26 & 1.92 & 5.32 \\
$\mathrm{OCH}_{3}$ & -0.26 & 4.25 & 2.32 & 4.71 \\
$\mathrm{CH}_{3}$ & -0.17 & 2.70 & 2.29 & 4.22 \\
$\mathrm{H}$ & 0 & 3.20 & 2.62 & 4.71 \\
$\mathrm{COPh}$ & 0.43 & 1.49 & 0.60 & - \\
$\mathrm{CN}$ & 0.66 & 1.92 & 1.89 & 1.58 \\
$\mathrm{NO}_{2}$ & 0.778 & 0.60 & 0.80 & 4.13 \\
\hline
\end{tabular}

aEquilibrium constants, $\mathrm{A}^{-}+\mathrm{ROH}^{K_{1}} \mathrm{~A}^{-} / \mathrm{ROH}$, at 273.2K.

${ }^{D}$ Data from reference 4.

observation that $\Delta S^{\circ}$ varies over a wide range in all 4 reaction series. Thus, little quantitative information can be gained by a consideration of the thermodynamic parameters for the reaction series.

The data in Table 3 show the effect of structure of the anion radicals on the ratio of equilibrium constants for the methanol reaction to those for the reaction with water, $K_{\mathrm{MeOH}} / K_{\mathrm{HOH}}$. The ratio for the substituted benzophenone anion radicals appears to be roughly linearly related to $\sigma_{p}$ with a negative slope. The same relationship appears to give a bell-shaped plot for the substituted nitrobenzenes while the ratio is more or less independent of $\sigma_{p}$ for the substituted benzaldehyde ${ }^{4}$ anion radicals. Although $K_{\mathrm{MeOH}} / K_{\mathrm{HOH}}$ varies differently for the 3 series of reactions there is one aspect of near consistency. In all cases excepting two, $\mathrm{PhCOC}_{6} \mathrm{H}_{4} \mathrm{NO}_{2}^{-}$and $\mathrm{O}_{2} \mathrm{~N}-\mathrm{C}_{6} \mathrm{H}_{4}-\mathrm{NO}_{2}{ }^{-}$, the ratio is significantly greater than unity which indicates that reactions involving methanol lie further to the right. Another approximate generality is that hydrogen bonding is stronger for benzaldehyde anion radicals ${ }^{4}$ than for benzophenone anion radicals and that $\mathrm{H}$-bonding is even weaker for the anion radicals of substituted nitrobenzenes.

\section{Experimental}

The reversible potential measurements by phase selective second harmonic a.c. voltammetry have been described in detail in a previous paper. ${ }^{5}$ The substituted benzophenones and nitrobenzenes were reagent grade and were purified by conventional methods before use. The instrumentation was similar to that described previously. ${ }^{6}$

\section{References}

1. Parker, V. D. Acta Chem. Scand. B 38 (1984) 125.

2. Parker, V. D. Acta Chem. Scand. B 38 (1984) 189.

3. Eliason, R. and Parker, V. D. Acta Chem. Scand. B 38 (1984) 741.

4. Svaan, M. and Parker, V. D. Acta Chem. Scand. B 39 (1985) 401.

5. Svaan, M. and Parker, V. D. Acta Chem. Scand. B 35 (1981) 559.

6. Ahlberg, E. and Parker, V. D. Acta Chem. Scand. B 34 (1980) 97.

Received 15 April, 1986. 